\title{
Article \\ Hot Deformation Behavior, Processing Maps and Microstructural Evolution of the Mg-2.5Nd-0.5Zn-0.5Zr Alloy
}

\author{
Junfei Ma ${ }^{1}$, Songhui Wang ${ }^{1,2, * \mathbb{D}}$, Jianlei Yang ${ }^{1,2}$, Wencong Zhang ${ }^{1,2}$, Wenzhen Chen ${ }^{1,2}$, Guorong Cui ${ }^{1,2}$ \\ and Guannan Chu 1,2 \\ 1 School of Materials Science and Engineering, Harbin Institute of Technology, Harbin 150001, China; \\ majingxuan0810@163.com (J.M.); jlyang@hit.edu.cn (J.Y.); zhangwencong@hit.edu.cn (W.Z.); \\ nclwens@hit.edu.cn (W.C.); cuiguorong2010@126.com (G.C.); chuguannan@hit.edu.cn (G.C.) \\ 2 Weihai Lightweight Materials and Forming Engineering Research Center, Weihai 264209, China \\ * Correspondence: wangsonghui91@126.com
}

check for updates

Citation: Ma, J.; Wang, S.; Yang, J.; Zhang, W.; Chen, W.; Cui, G.; Chu, G. Hot Deformation Behavior, Processing Maps and Microstructural Evolution of the

Mg-2.5Nd-0.5Zn-0.5Zr Alloy. Materials 2022, 15, 1745. https:// doi.org/10.3390/ma15051745 Academic Editor: Antonino Squillace

Received: 5 February 2022

Accepted: 22 February 2022

Published: 25 February 2022

Publisher's Note: MDPI stays neutral with regard to jurisdictional claims in published maps and institutional affiliations.

Copyright: (C) 2022 by the authors. Licensee MDPI, Basel, Switzerland. This article is an open access article distributed under the terms and conditions of the Creative Commons Attribution (CC BY) license (https:// creativecommons.org/licenses/by/ $4.0 /$ )

\begin{abstract}
Isothermal hot compression experiments were conducted on $\mathrm{Mg}-2.5 \mathrm{Nd}-0.5 \mathrm{Zn}-0.5 \mathrm{Zr}$ alloy to investigate hot deformation behavior at the temperature range of $573-773 \mathrm{~K}$ and the strain rate range of $0.001 \mathrm{~s}^{-1}-10 \mathrm{~s}^{-1}$ using a Gleeble-3500D thermomechanical simulator. The results showed that the rheological curve showed a typical work hardening stage, and there were three different stages: work hardening, transition and steady state. A strain compensation constitutive model was established to predict the flow stress of the $\mathrm{Mg}-2.5 \mathrm{Nd}-0.5 \mathrm{Zn}-0.5 \mathrm{Zr}$ alloy, and the results proved that it had high predictability. The main deformation mechanism of the $\mathrm{Mg}-2.5 \mathrm{Nd}-0.5 \mathrm{Zn}-0.5 \mathrm{Zr}$ alloy was dislocation climbing. The processing maps were established to distinguish the unstable region from the working region. The maps showed that the instability generally occurred at high strain rates and low temperatures, and the common forms of instability were cracking and flow localization. The optimum machining range of the alloy was determined to be $592-773 \mathrm{~K}$ and $0.001-0.217 \mathrm{~s}^{-1}$. With the increase in deformation temperature, the grain size of the alloy grew slowly at the 573-673 K temperature range and rapidly at the $673-773 \mathrm{~K}$ temperature range.
\end{abstract}

Keywords: Mg-2.5Nd-0.5Zn-0.5Zr alloy; hot deformation; microstructure; constitutive equations

\section{Introduction}

Mg alloys have the benefits of low density, high stiffness, high specific strength and machinability [1]. They have been widely used in aerospace, automotive, electronics, medical devices and other industries [2-4]. The mechanical and structural properties of $\mathrm{Mg}$ alloys and their response to stresses are currently a hot topic [5-7]. Many studies have shown that rare earth (RE) elements could significantly strengthen Mg alloys [8-12]. Although adding a large number of RE elements can effectively improve the mechanical properties of an alloy, the cost increases greatly, which limits the wide application of $\mathrm{Mg}$ alloys with high RE content $[13,14]$. Therefore, the rapid development of high-performance low-RE content $\mathrm{Mg}$ alloys is urgent.

Mg-Nd-Zn-Zr alloys are favored by many researchers for their excellent mechanical properties and low RE content [15-18]. However, the limited thermoplastic processing conditions of Mg-RE alloys restrict their further application [19]. Therefore, a comprehensive understanding of the thermal deformation behavior of $\mathrm{Mg}-\mathrm{Nd}-\mathrm{Zn}-\mathrm{Zr}$ alloys was necessary for the development and engineering application of low RE content $\mathrm{Mg}$ alloys. Up to now, the research on $\mathrm{Mg}-\mathrm{Nd}-\mathrm{Zn}-\mathrm{Zr}$ alloys mainly focused on the effect of casting and heat treatment on the microstructure and properties of the alloy $[11,14,20]$. Cast alloys generally have many defects (e.g., coarse structure, low strength and poor plasticity, etc.) $[11,14,18,20,21]$. Hot extrusion was shown to be an effective method to refine the microstructure, eliminate casting defects and improve the properties of alloys, which can significantly improve its hot formability [21]. However, there was little existing research on the hot working ability 
of the extruded Mg-Nd-Zn-Zr alloys. Therefore, it was of great significance to study the thermal deformation behavior and microstructure evolution of the extruded $\mathrm{Mg}-\mathrm{Nd}-\mathrm{Zn}-\mathrm{Zr}$ alloy, and to optimize its thermal processing parameters using the processing map.

It is well known that constitutive equation analysis has become an effective method to present the thermal deformation behavior of metal materials [22]. The flow behavior of materials during thermal deformation is complicated and is mainly affected by deformation parameters (e.g., strain rate, deformation temperature and deformation degree, etc.). Hence, a suitable constitutive model should consider the coupling effects of multiple factors simultaneously. As an improved form of the hyperbolic sinusoidal Arrhenius model, the strain-compensated Arrhenius equation can meet the above requirements and has been diffusely used in studies of thermal deformation of metal materials (e.g., magnesium alloy [23,24], aluminum alloy [25,26], titanium alloy [27,28], etc.). For example, $\mathrm{Hu}$ et al. [29] constructed the strain-compensated Arrhenius constitutive model for Mg-8.5Gd$4.5 \mathrm{Y}-0.8 \mathrm{Zn}-0.4 \mathrm{Zr}$ alloy. The predicted values were in good agreement with the experimental results. Zhang et al. [30] investigated the deformation behavior of homogenized Mg-5.25Gd$2.73 \mathrm{Y}-0.51 \mathrm{Zr}$ alloy, and a constitutive equation of strain compensation was proposed. The experimental results were in good agreement with the predicted results. Thus far, the literature has showed that there are few existing studies on the thermal deformation behavior of $\mathrm{Mg}-\mathrm{Nd}-\mathrm{Zn}-\mathrm{Zr}$ alloys using the strain-compensated Arrhenius model, especially the studies on the strain-compensated constitutive equation of extruded $\mathrm{Mg}-\mathrm{Nd}-\mathrm{Zn}-\mathrm{Zr}$ alloys.

The dynamic material model (DMM) of Prasad based on processing maps is a powerful tool for optimizing thermal processing and controlling the microstructure of a variety of alloys [23,25-27]. For instance, Xia et al. [23] investigated the hot workability of Mg-6.85Gd$4.52 \mathrm{Y}-1.15 \mathrm{Nd}-0.55 \mathrm{Zr}$ alloy by compression tests and established processing maps. The suitable hot working condition for the alloy was determined to be $773 \mathrm{~K}$ and $0.05 \mathrm{~s}^{-1}$. Zheng et al. [31] studied the hot tensile deformation behavior of extruded $\mathrm{Mg}-2.5 \mathrm{Nd}-0.2 \mathrm{Zn}$ $0.1 \mathrm{Zr}$ alloy at a temperature range of $200-400{ }^{\circ} \mathrm{C}$ and a strain rate of $0.001-1 \mathrm{~s}^{-1}$, and established the hot working diagram. The optimum hot working condition temperature was $380{ }^{\circ} \mathrm{C}$ and the strain rate was $0.006 \mathrm{~s}^{-1}$.

In this paper, the deformation behavior of the extruded $\mathrm{Mg}-2.5 \mathrm{Nd}-0.5 \mathrm{Zn}-0.5 \mathrm{Zr}$ alloy was investigated using the Gleeble-3500D thermal simulator. A strain-compensated Arrhenius constitutive equation was established to predict the flow stress. A DMM-based processing chart was constructed, which provided important guidance for optimizing thermal deformation parameters. In addition, the evolution of the microstructure of the alloy was analyzed.

\section{Material and Experimental Procedures}

The initial material (provided by Guizhou Anji Nonferrous Casting Co., Ltd., Guizhou, China) was an Mg-2.5Nd-0.5Zn-0.5Zr (wt \%) extrusion bar with a diameter of $25 \mathrm{~mm}$. The actual chemical composition (Mg-2.58Nd-0.54Zn-0.54Zr, wt \%) was examined by X-ray fluorescence spectrometer (ZSX-100e, Tokyo, Japan). The compression sample was processed along the extrusion direction (ED), and the cylindrical sample was $\Phi 8 \times 12 \mathrm{~mm}$. Firstly, the surfaces were polished smooth with 400\#, 800\#, 1200\# and 1500\# sandpaper, and then the samples were cleaned by ultrasonic shock for 5 mins in acetone and alcohol solution, in that order. The isothermal compression experiment was conducted using the Gleeble-3500D thermal simulator. Experimental parameters are shown in Figure 1. All samples were compressed to the true strain of 0.7 , and then the sample were taken out for quenching to retain the high-temperature deformation structure. Note that the graphite papers were placed at the ends of the samples to avoid the experimental error caused by friction before the experiment. 
(a)

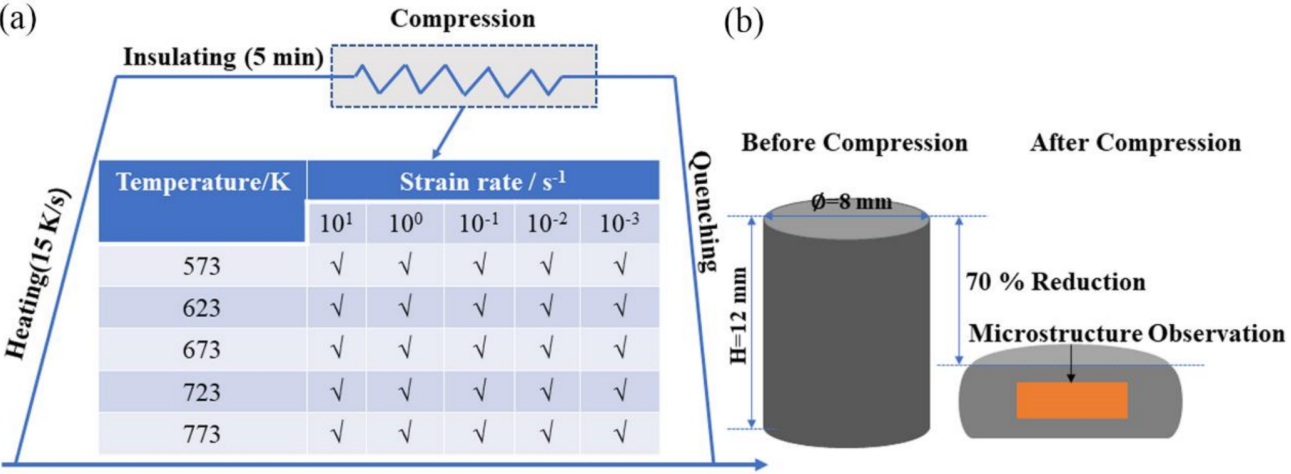

Figure 1. Diagram of the isothermal compression process. (a) experimental process; (b) EBSD sample.

With the inhomogeneous deformation of the sample taken into consideration, the microstructure was observed in the center area of the longitudinal section, as shown in the brown area in Figure 1b. The microstructure analysis was undertaken by electron backscatter diffraction (EBSD, MERLIN Compact, Oberkochen, Germany). The EBSD samples were first prepared by mechanical polishing, then electropolishing $\left(5: 3 \mathrm{C}_{2} \mathrm{H}_{5} \mathrm{OH}\right.$ and $\mathrm{H}_{3} \mathrm{PO}_{4}$ electrolyte, electropolishing for $2 \mathrm{~min}$ at $0.5 \mathrm{~A}$ and $5 \mathrm{~min}$ at $0.25 \mathrm{~A}$ ).

\section{Results and Discussion}

\subsection{Stress-Strain Curves}

Figure 2 exhibits the true stress-strain curves of the $\mathrm{Mg}-2.5 \mathrm{Nd}-0.5 \mathrm{Zn}-0.5 \mathrm{Zr}$ alloy under different deformation parameters. It reflects the process of work hardening and dynamic recrystallization (DRX) during deformation. Each stress-strain curve includes the workhardening stage, dynamic-softening stage and dynamic-equilibrium stage. At the initial stage of deformation, with the accumulation of compression, the flow stress increased sharply to the maximum stress value. As the hot compression continued, varying degrees of softening arose so that the flow stress gradually decreased and finally reached the equilibrium state. Take the deformation condition of $573 \mathrm{~K} / 0.001 \mathrm{~s}^{-1}$ in Figure $2 \mathrm{a}$ as an example: when the compression strain was between 0 and 0.04 , the flow stress of the $\mathrm{Mg}-2.5 \mathrm{Nd}-0.5 \mathrm{Zn}-0.5 \mathrm{Zr}$ alloy increased rapidly from $0 \mathrm{MPa}$ to $\sim 90 \mathrm{MPa}$, which was attributed to the work-hardening phenomenon caused by the proliferation of dislocation, delivery entanglement and dislocation movement obstruction [32-35]. With the increase in strain, dynamic recovery (DRV) increased and work hardening decreased. However, DRV could not completely offset the distortion energy caused by work hardening, and the increased rate of flow stress decreased. DRX occurred when the critical strain reached 0.06. DRX significantly reduced dislocation density, and the flow stress reached its peak at 103.4 MPa. After further accumulation of strain variables, the softening effect of DRV and DRX gradually exceeded the work-hardening effect, and the flow stress showed a downward trend. When the strain reached about 0.5 , work hardening and dynamic softening reached a dynamic equilibrium, and the flow stress tended to equilibrium. 

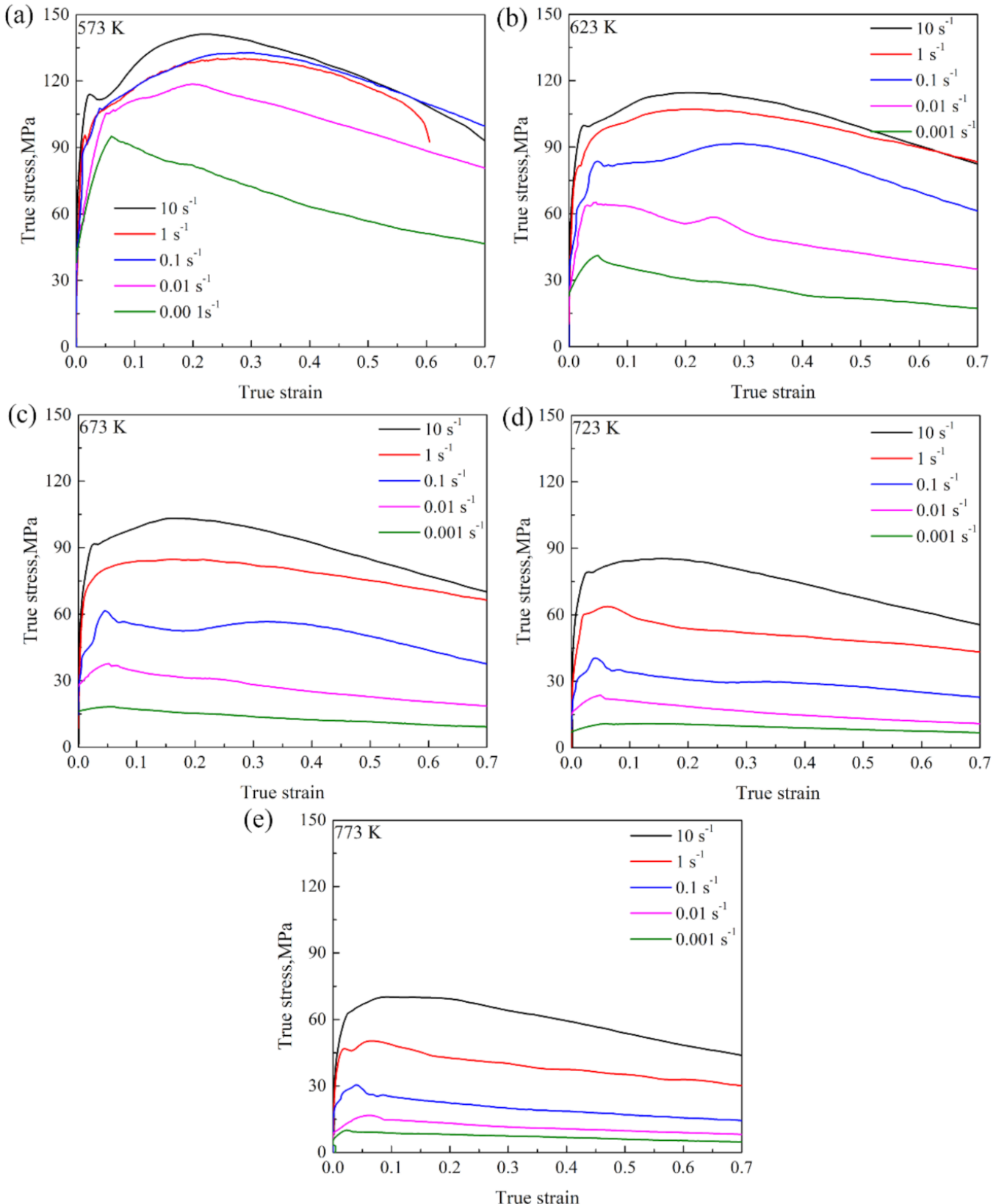

Figure 2. True stress-strain curves of the $\mathrm{Mg}-2.5 \mathrm{Nd}-0.5 \mathrm{Zn}-0.5 \mathrm{Zr}$ alloy at various hot deformation temperatures: (a) $573 \mathrm{~K}$, (b) $623 \mathrm{~K}$, (c) $673 \mathrm{~K}$, (d) $723 \mathrm{~K}$, (e) $773 \mathrm{~K}$.

Figure 3 presents the peak stress of the Mg-2.5Nd-0.5Zn-0.5Zr alloy under different deformation conditions. At the same strain rate, the peak stress of the Mg- $2.5 \mathrm{Nd}-0.5 \mathrm{Zn}-0.5 \mathrm{Zr}$ alloy decreased gradually with the increase in deformation temperature. This was mainly because the atomic kinetic energy of the alloy increased gradually with the increasing deformation temperature, which led to a decrease in interatomic bonding ability and a decrease in the deformation resistance of the alloy [2]. Meanwhile, the thermal activation energy of the $\mathrm{Mg}-2.5 \mathrm{Nd}-0.5 \mathrm{Zn}-0.5 \mathrm{Zr}$ alloy decreased with the increase in temperature, which led to an increase in actual dislocations and slip systems in the microstructure, and the dynamic softening effect was obvious. At the same deformation temperature, the peak stress of the alloy decreased with the decrease in strain rate, which could be attributed to the fact that the dislocation generated during the low strain rate compression process had had enough time to start, the dislocation entanglement phenomenon was weakened and the dynamic softening effect was significant [30]. Meanwhile, the lower deformation rate 
could have improved the stress concentration caused by uneven grain deformation. The increase in temperature and the decrease in strain rate also led to the nonlinear decrease in

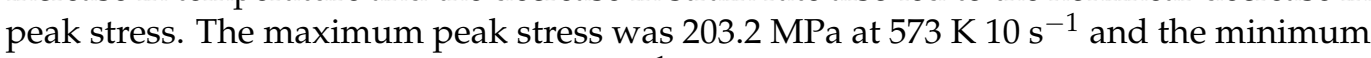

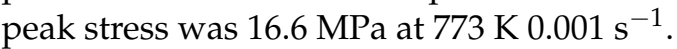

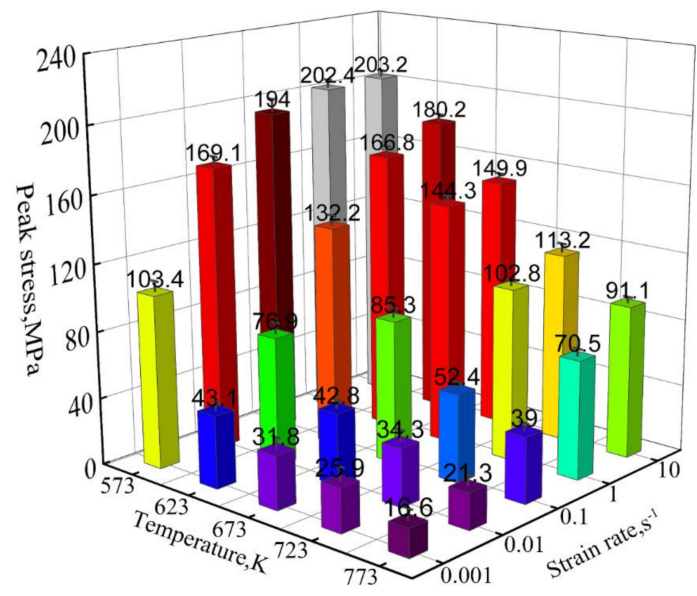

Figure 3. Peak flow stress of the Mg-2.5Nd-0.5Zn-0.5Zr alloy at different deformation conditions.

\subsection{Constitutive Model}

\subsubsection{Constitutive Equations}

An Arrhenius-type equation was used to characterize the relationship between the hot-deformation parameters [22-31], as follows:

$$
\begin{gathered}
\dot{\varepsilon}=\operatorname{AF}(\sigma) \exp \left(-\frac{\mathrm{Q}}{\mathrm{RT}}\right) \\
\mathrm{F}(\sigma)=\left\{\begin{array}{c}
\sigma^{\mathrm{n}_{1}}(\alpha \sigma<0.8) \\
\exp (\beta \sigma)(\alpha \sigma>0.8) \\
\left.[\sinh (\alpha \sigma)]^{\mathrm{n}} \text { (For all }\right)
\end{array}\right.
\end{gathered}
$$

where $\dot{\varepsilon}$ was the strain rate $\left(\mathrm{s}^{-1}\right), \sigma$ was the flow stress (MPa), Q was the apparent deformation-activation energy $(\mathrm{kJ} / \mathrm{mol}), \mathrm{T}$ was the deformation temperature $(\mathrm{K}), \mathrm{R}$ was the gas constant $(\mathrm{R}=8.314 \mathrm{~J} / \mathrm{mol} \mathrm{K})$, and $\mathrm{A}, \mathrm{n}_{1}, \alpha, \beta$ were material constants. In addition, $\alpha=\frac{\beta}{n_{1}}$.

$$
\begin{gathered}
\ln \dot{\varepsilon}=\ln \mathrm{A}+\mathrm{n}_{1} \ln \sigma-\frac{\mathrm{Q}}{\mathrm{RT}} \\
\ln \dot{\varepsilon}=\ln \mathrm{A}+\beta \sigma-\frac{\mathrm{Q}}{\mathrm{RT}} \\
\ln \dot{\varepsilon}=\ln \mathrm{A}+\operatorname{nln}[\sinh (\alpha \sigma)]-\frac{\mathrm{Q}}{\mathrm{RT}}
\end{gathered}
$$

From Equations (6)-(9), the parameters $n_{1}, \beta, n$ and $Q$ could be expressed as:

$$
\begin{gathered}
\mathrm{n}_{1}=\left(\frac{\partial \ln \dot{\varepsilon}}{\partial \ln \sigma}\right)_{\mathrm{T}} \\
\beta=\left(\frac{\partial \ln \dot{\varepsilon}}{\partial \sigma}\right)_{\mathrm{T}} \\
\mathrm{n}=\left[\frac{\partial \ln \dot{\varepsilon}}{\partial \ln \sinh (\alpha \sigma)}\right]_{\mathrm{T}} \\
\mathrm{Q}=\mathrm{nR}\left[\frac{\partial \ln \sinh (\alpha \sigma)}{\partial(1 / \mathrm{T})}\right]_{\mathrm{T}}
\end{gathered}
$$


The relationship between strain rate $(\dot{\varepsilon})$ and deformation temperature $(\mathrm{T})$ was expressed as [22]:

$$
\mathrm{Z}=\dot{\varepsilon} \exp \left(-\frac{\mathrm{Q}}{\mathrm{RT}}\right)=\mathrm{A}[\sinh (\alpha \sigma)]^{\mathrm{n}}
$$

Linearizing Equation (11) by logarithmic processing:

$$
\ln \mathrm{Z}=\ln \mathrm{A}+\mathrm{n}[\sinh (\alpha \sigma)]
$$

In this study, the detailed steps to determine the material constants were illustrated by taking a strain of 0.4 as an example. In Figure 4, based on Equations (6)-(8), the values of $\mathrm{n}_{1}$, $\beta$ and $n$ were calculated from the slopes of $\ln \sigma-\ln \dot{\varepsilon}, \sigma-\ln \dot{\varepsilon}$, and $\ln [\sinh (\alpha \sigma)]-\ln \dot{\varepsilon}, Q$ and $\ln \mathrm{A}$. The $\beta, \alpha, \mathrm{n}, \mathrm{n}_{1}, \mathrm{Q}$, and $\ln \mathrm{A}$ were $0.121014,0.021944,3.778,5.5147,171.929 \mathrm{~kJ} / \mathrm{mol}$ and 27.65 , respectively.
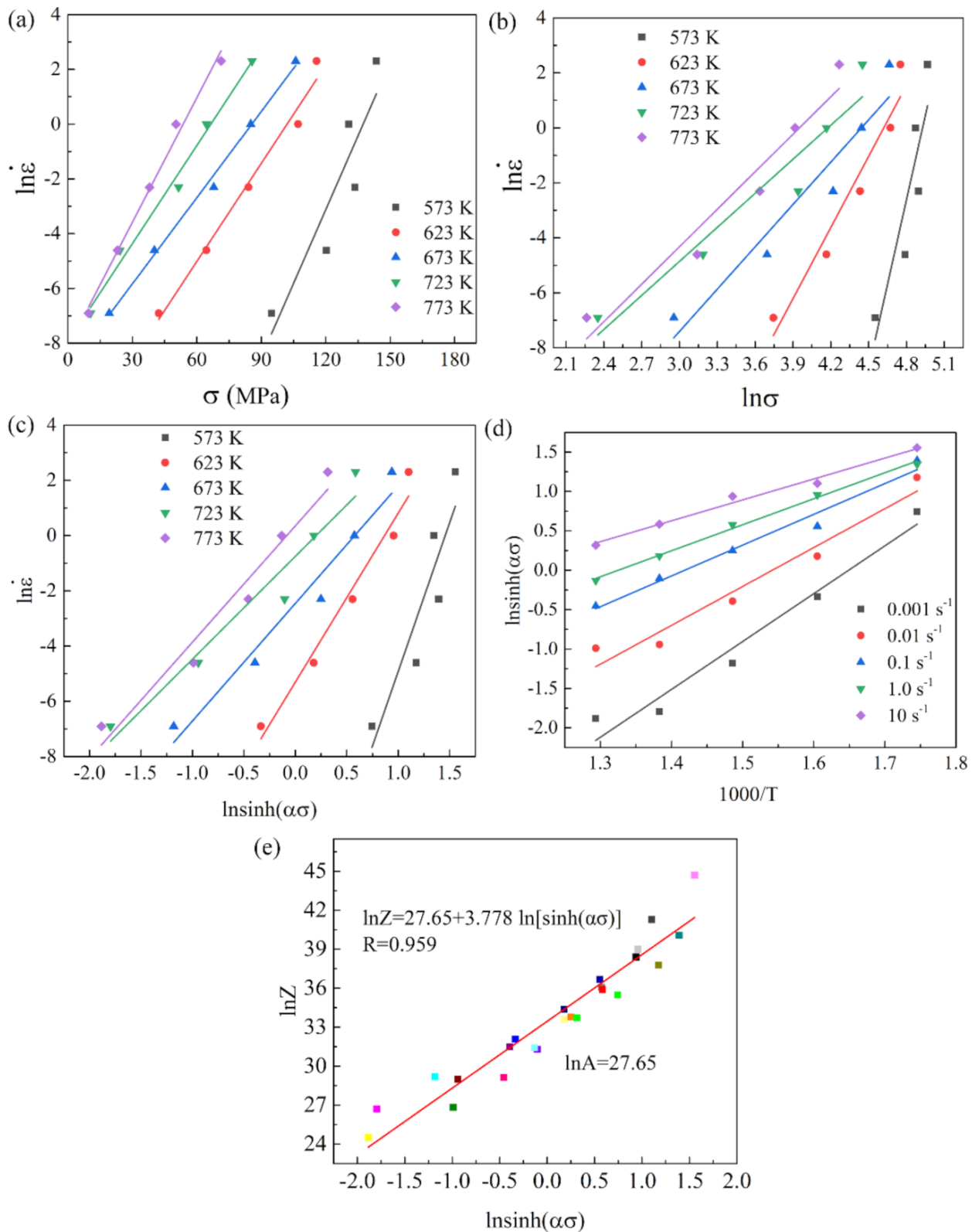

Figure 4. Linear relationships of (a) $\sigma-\ln \dot{\varepsilon},(\mathbf{b}) \ln \sigma-\ln \dot{\varepsilon},(\mathbf{c}) \ln [\sinh (\alpha \sigma)]-\ln \dot{\varepsilon}$, (d) $1000 / \mathrm{T}-\ln [\sinh (\alpha \sigma)]$ and $(\mathbf{e}) \ln Z-\ln [\sinh (\alpha \sigma)]$. 
The flow stress can be expressed as:

$$
\sigma=\frac{1}{\alpha} \ln \left\{(\mathrm{Z} / \mathrm{A})^{1 / \mathrm{n}}+\left[(\mathrm{Z} / \mathrm{A})^{2 / \mathrm{n}}+1\right]^{1 / 2}\right\}
$$

Hence, the flow stress of the $\mathrm{Mg}-2.5 \mathrm{Nd}-0.5 \mathrm{Zn}-0.5 \mathrm{Zr}$ alloy when the strain was 0.4 can be expressed as:

$$
\sigma=45.5705 \ln \left\{\left(Z / \mathrm{e}^{27.65}\right)^{\frac{1}{3.778}}+\left[\left(\mathrm{Z} / \mathrm{e}^{27.65}\right)^{\frac{2}{3.778}}+1\right]^{\frac{1}{2}}\right\}
$$

\subsubsection{Strain Compensation Analysis}

It can be seen from Figure 2 that the true strain variable $(\varepsilon)$ also had a great effect on the flow stress of the Mg-2.5Nd-0.5Zn-0.5Zr alloy. However, in previous studies [3,23,30], a single strain was usually used to establish a simple constitutive equation, and strain-factor parameters were not added in Equation (13). The result showed that the calculated thermal $Q$ could not reflect the real activation energy in the actual deformation process. Therefore, based on the true stress-strain curve of the $\mathrm{Mg}-2.5 \mathrm{Nd}-0.5 \mathrm{Zn}-0.5 \mathrm{Zr}$ alloy in Figure 2, the material constants, corresponding to the true strain from 0.1 to 0.65 , were calculated using the method of $\varepsilon=0.4$ with 0.05 intervals. Then, a series of $\alpha, n, Q$ and $\ln A$ values were polynomially fitted with the true strain, as shown in Equation (14). The function relation between the material constants $\alpha, n, Q, \ln A$ and the true strain was established. Figure 5 shows the result of sixth-degree polynomial fitting, and the polynomial coefficients are shown in Table 1.

$$
\begin{gathered}
\alpha=B_{0}+B_{1} \varepsilon^{1}+B_{2} \varepsilon^{2}+B_{3} \varepsilon^{3}+B_{4} \varepsilon^{4} \ldots+B_{m} \varepsilon^{m} \\
n=C+C_{1} \varepsilon^{1}+C_{2} \varepsilon^{2}+C_{3} \varepsilon^{3}+C_{4} \varepsilon^{4} \ldots+C_{m} \varepsilon^{m} \\
Q=D_{0}+D_{1} \varepsilon^{1}+D_{2} \varepsilon^{2}+D_{3} \varepsilon^{3}+D_{4} \varepsilon^{4} \ldots+D_{m} \varepsilon^{m} \\
\ln A=E_{0}+E_{1} \varepsilon^{1}+E_{2} \varepsilon^{2}+E_{3} \varepsilon^{3}+E_{4} \varepsilon^{4} \ldots+E_{m} \varepsilon^{m}
\end{gathered}
$$

The constant equation with the strain factor $(\varepsilon)$ was coupled to the constructed constitutive equation. Therefore, the hyperbolic sinusoidal Arrhenius constitutive equation of the $\mathrm{Mg}-2.5 \mathrm{Nd}-0.5 \mathrm{Zn}-0.5 \mathrm{Zr}$ alloy was obtained at $573-773 \mathrm{~K}$ and a strain rate of $10.0-0.001 \mathrm{~s}^{-1}$, as shown in Equation (15).

$$
\begin{gathered}
\sigma=\frac{1}{\alpha} \ln \left\{(\mathrm{Z} / \mathrm{A})^{1 / \mathrm{n}}+\left\{(\mathrm{Z} / \mathrm{A})^{2 / \mathrm{n}}+1\right]^{1 / 2}\right\} \\
\alpha(\varepsilon)=0.01+0.09 \varepsilon^{1}-0.65 \varepsilon^{2}+2.54 \varepsilon^{3}-5.09 \varepsilon^{4}+5.03 \varepsilon^{5}-1.93 \varepsilon^{6} \\
\mathrm{n}(\varepsilon)=15.56-170.07 \varepsilon^{1}+1127.68 \varepsilon^{2}-4034.49 \varepsilon^{3}+7904.61 \varepsilon^{4}-7960.32 \varepsilon^{5}+3217.49 \varepsilon^{6} \\
\mathrm{Q}(\varepsilon)=507.57-5781.23 \varepsilon^{1}+43757.45 \varepsilon^{2}-170718.30 \varepsilon^{3}+354866.01 \varepsilon^{4}-373319.75 \varepsilon^{5}+156209.15 \varepsilon^{6} \\
\operatorname{InA}(\varepsilon)=88.95-1033.31 \varepsilon^{1}+7893.32 \varepsilon^{2}-31410.53 \varepsilon^{3}+66790.89 \varepsilon^{4}-71967.43 \varepsilon^{5}+30880.84 \varepsilon^{6}
\end{gathered}
$$

Table 1. The coefficient of material constants and true strain during fitting polynomials.

\begin{tabular}{cccccccc}
\hline \multirow{2}{*}{$\begin{array}{c}\text { Material } \\
\text { Constants }\end{array}$} & \multicolumn{7}{c}{ Coefficients } \\
\cline { 2 - 8 } & $\varepsilon^{0}$ & $\mathcal{\varepsilon}^{1}$ & $\mathcal{\varepsilon}^{2}$ & $\mathcal{\varepsilon}^{3}$ & $\mathcal{\varepsilon}^{4}$ & $\mathcal{\varepsilon}^{5}$ & $\mathcal{\varepsilon}^{6}$ \\
\hline$\alpha$ & 0.01 & 0.09 & -0.65 & 2.51 & -5.09 & 5.03 & -1.93 \\
$\mathrm{n}$ & 15.56 & -170.07 & 1127.68 & -4034.49 & 7904.61 & -7960.32 & 3217.49 \\
$\mathrm{Q}$ & 507.57 & -5781.23 & 43757.45 & -170718.30 & 354866.01 & -373319.75 & 156209.15 \\
$\ln \mathrm{A}$ & 88.95 & -1033.31 & 7893.32 & -31410.53 & 66790.89 & -71967.43 & 30880.84 \\
\hline
\end{tabular}



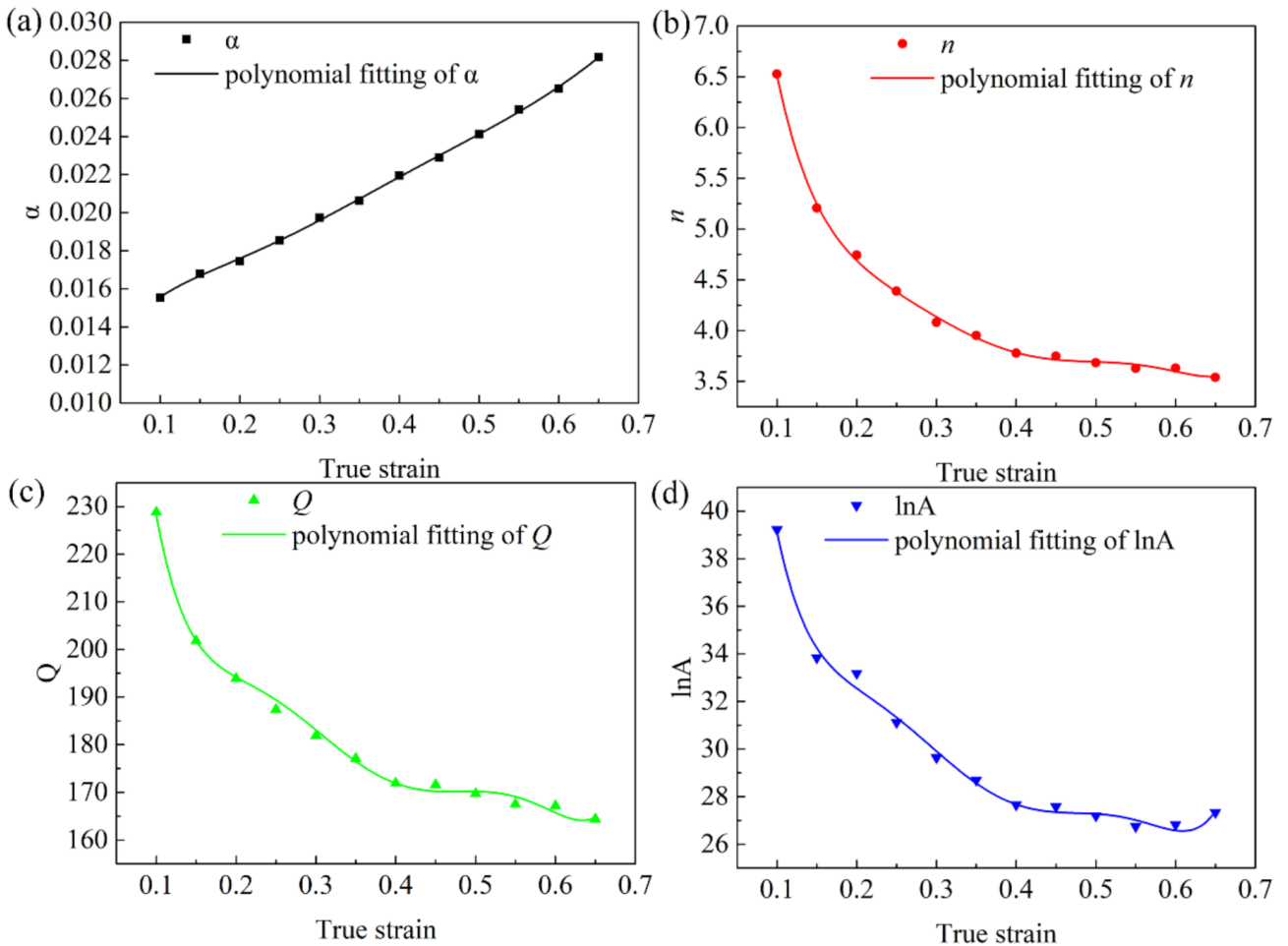

Figure 5. Plots of the compensation functions of different material parameters: (a) a, (b) n, (c) Q, and (d) $\ln \mathrm{A}$.

\subsubsection{Deformation Mechanism}

The deformation mechanism of the alloy was mainly affected by the stress exponent (n) and $\mathrm{Q}$ in the constitutive model. The change of $\mathrm{n}$ value was related to the movement of crystal defects during deformation. In Table 2 , different $\mathrm{n}$ values correspond to different deformation mechanisms. In particular, according to Equations (8) and (9), the corresponding $Q$ and $n$ under strain $(\varepsilon=0.4)$ were calculated. The calculated results are presented in Table 3. Figure 6 shows the three-dimensional activation energy distribution of the $\mathrm{Mg}-2.5 \mathrm{Nd}-0.5 \mathrm{Zn}-0.5 \mathrm{Zr}$ alloy at a strain of 0.4 . The $\mathrm{Q}$ decreased with the increase in strain rate and deformation temperature. The $Q$ was in the range of $97.1-271.9 \mathrm{~kJ} / \mathrm{mol}$. The grain boundary diffusion activation energy $\left(\mathrm{Q}_{\mathrm{GB}}\right.$ ) of pure $\mathrm{Mg}$ was $82-105 \mathrm{~kJ} / \mathrm{mol}$, and the lattice self-diffusion activation energy $\left(Q_{L}\right)$ of pure $\mathrm{Mg}$ was $135 \mathrm{~kJ} / \mathrm{mol}[36,37]$. According to Figure $5 \mathrm{~b}$ and Table 3 , when the strain rate was $10 \mathrm{~s}^{-1}$ and the deformation temperature was 723-773 K (the black area in Table 3), the $Q$ of the alloy was close to the $Q_{G B}$ of pure $\mathrm{Mg}$, and the deformation mechanism of the alloy was dislocation climbing controlled by grain boundary diffusion. The $Q$ of the alloy was greater than the $Q_{L}$ and less than the $\mathrm{Q}_{\mathrm{GB}}$ of pure $\mathrm{Mg}$ at strain rates of $1-10 \mathrm{~s}^{-1}$ and $623-773 \mathrm{~K}$ (the blue area in Table 3), and the deformation mechanism of the alloy was a dislocation climbing mechanism. The $\mathrm{Q}$ of the alloy was greater than the $\mathrm{Q}_{\mathrm{L}}$ of pure $\mathrm{Mg}$ at strain rates of $0.001-10 \mathrm{~s}^{-1}$ and $573-773 \mathrm{~K}$ (the red area in Table 3); these results indicated that there were other mechanisms besides lattice diffusion that led to the increase in the $Q$ of thermal deformation [38]. The deformation was controlled by the joint mechanism of second-phase pinning and dislocation, and the source of the pinning may be related to solute atoms and dynamic precipitates [39]. Therefore, higher energy was required to induce dislocation climbing. Similarly, this phenomenon has been reported in research be Lei et al. [26]. 
Table 2. Stress exponent values and associated deformation mechanisms.

\begin{tabular}{ccc}
\hline (n) Values & Deformation Mechanisms & Ref. \\
\hline 2 & Grain boundary sliding & {$[25]$} \\
3 & Viscous glide of dislocation & {$[26]$} \\
5 & Dislocation climb & {$[40]$} \\
8 and above & Cross-slip of screw dislocations/Constant & {$[36]$} \\
\hline
\end{tabular}

Table 3. The activation energy $(\mathrm{Q})$ and stress exponent $(\mathrm{n})$ of the alloy at a strain of 0.4 .

\begin{tabular}{|c|c|c|c|c|c|c|}
\hline \multirow{2}{*}{ Temperature (K) } & \multicolumn{5}{|c|}{$\mathrm{Q}(\mathrm{kJ} / \mathrm{mol})$} & \multirow{2}{*}{$\mathbf{n}$} \\
\hline & $0.001 \mathrm{~s}^{-1}$ & $0.01 \mathrm{~s}^{-1}$ & $0.1 \mathrm{~s}^{-1}$ & $1 \mathrm{~s}^{-1}$ & $10 \mathrm{~s}^{-1}$ & \\
\hline 573 & 271.9 & 268.9 & 224.3 & 197.7 & 144.4 & 4.86 \\
\hline 623 & 203.5 & 201.3 & 167.9 & 148.1 & 108.1 & 3.64 \\
\hline 673 & 199.3 & 197.1 & 164.4 & 144.9 & 105.9 & 3.56 \\
\hline 723 & 197.8 & 195.7 & 163.2 & 143.9 & 105.0 & 3.54 \\
\hline 773 & 182.7 & 180.7 & 150.7 & 132.8 & 97.1 & 3.27 \\
\hline
\end{tabular}

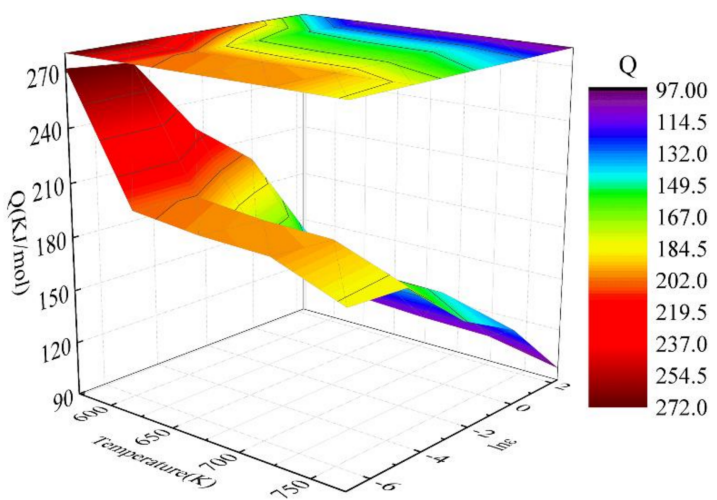

Figure 6. 3D activation energy map of the $\mathrm{Mg}-2.5 \mathrm{Nd}-0.5 \mathrm{Zn}-0.5 \mathrm{Zr}$ alloy at a strain of 0.4 .

\subsubsection{Assessment of the Constitutive Model}

To further verify the applicability of the true strain-coupled high-temperature constitutive equation established in the above section, the correlation coefficient $R$, square root error (RMSE) and average relative error (AARE) were used for comprehensive evaluation $[4,26,28]$. Assessment of the predictability of the devised model was performed by the RMSE, R, and AARE presented in Equations (16)-(18), respectively [26,28].

$$
\begin{aligned}
& \text { RMSE }=\sqrt{\sum_{i=1}^{N}\left(E_{i}-P_{i}\right)^{2} / N} \\
& R=\frac{\sum_{i=1}^{N}\left(E_{i}-\bar{E}\right)\left(P_{i}-\bar{P}\right)}{\sqrt{\sum_{i=1}^{N}\left(E_{i}-\bar{E}\right)^{2}\left(P_{i}-\bar{P}\right)^{2}}} \\
& \text { AARE }=\frac{1}{N}=\sum_{i=1}^{N}\left|\frac{E_{i}-P_{i}}{E_{i}}\right|
\end{aligned}
$$

From Equations (16)-(18), E was the experimental flow stress, P was the predicted flow stress, and i stands for the ordinal. $\mathrm{N}$ was the number of data sets for statistics. As shown in Figure 7, the deviation between the experimental flow stress (solid line) and the predicted value (scatter diagram) of the established high-temperature constitutive 
model was small, indicating that the prediction of flow stress by the constitutive model was relatively accurate. In Figure 8, the RMSE of the model was 5.6, the predictability of the established high-temperature constitutive model was $99.6 \%$ and the AARE was only $6.1 \%$, which verified the high accuracy of the constitutive model. It was shown that the constitutive model could accurately describe the relationship between the flow stress, deformation temperature and strain rate of the $\mathrm{Mg}-2.5 \mathrm{Nd}-0.5 \mathrm{Zn}-0.5 \mathrm{Zr}$ alloy studied.
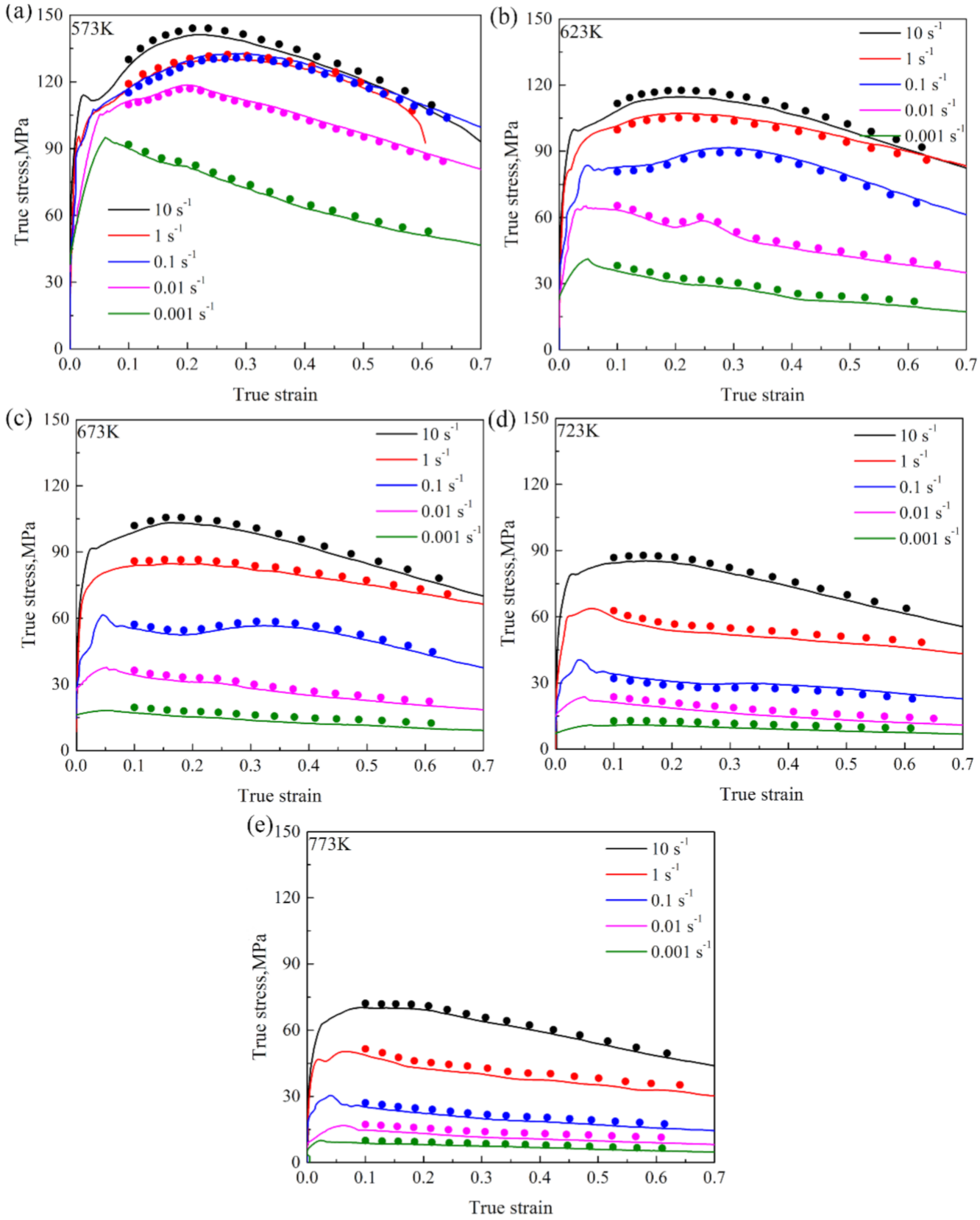

Figure 7. Experimental (solid lines) and predicted (scatter plot) flow stress of the alloy at (a) $573 \mathrm{~K}$, (b) $623 \mathrm{~K},(\mathbf{c}) 673 \mathrm{~K},(\mathbf{d}) 723 \mathrm{~K}$ and (e) $773 \mathrm{~K}$. 


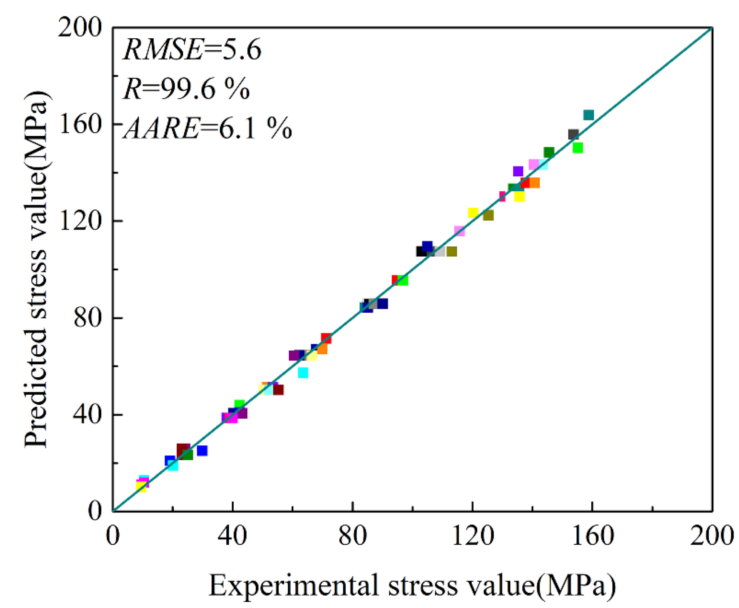

Figure 8. Correlation between the experimental and predicted flow stress.

\subsection{Processing Map}

Prasad et al. [26,27] developed a processing map based on DMM. In this model, the total power dissipated $(\mathrm{P})$ consisted of two parts. One was the power dissipated by plastic deformation, which was expressed by $\mathrm{G}$ content, and the other was the power dissipated by microstructure evolution (e.g., DRV, DRX and phase transition, etc.), represented by J content. Therefore, $\mathrm{P}$ was expressed by the following equation:

$$
\mathrm{P}=\mathrm{G}+\mathrm{J}=\sigma \dot{\varepsilon}=\int_{0}^{\varepsilon} \sigma \mathrm{d} \dot{\varepsilon}+\int_{0}^{\sigma} \dot{\varepsilon} \mathrm{d} \sigma
$$

For arbitrary strain rate and deformation temperature, the power distribution between J and $G$ was described as follows [29,31]:

$$
\left(\frac{\partial \mathrm{J}}{\partial \mathrm{G}}\right)_{\mathrm{T}, \dot{\varepsilon}}=\left(\frac{\partial \ln \sigma}{\partial \ln \dot{\varepsilon}}\right)_{\mathrm{T}, \dot{\varepsilon}}=\mathrm{m}
$$

$m$ was the strain-rate sensitivity of the material. The power dissipation efficiency ( $\eta$ ) was introduced to characterize the power dissipation during the evolution of the microstructure, and it was calculated using the following equation [25]:

$$
\eta=\frac{\mathrm{J}}{\mathrm{J}_{\max }}=\frac{2 \mathrm{~m}}{\mathrm{~m}+1}
$$

The variation of $\eta$ with strain rate and deformation temperature constitutes the power dissipation diagram. This graph was a contour map of the variation of deformation temperature-strain rate field efficiency, with different regions representing specific deformation mechanisms. Furthermore, a criterion of flow instability was defined using the extremum principle of irreversible thermodynamics $[36,40]$ :

$$
\xi(\dot{\varepsilon})=\frac{\partial \ln (\mathrm{m} / \mathrm{m}+1)}{\partial \ln \dot{\varepsilon}}+\mathrm{m} \leq 0
$$

Flow instability occurred when the $\xi(\dot{\varepsilon})$ was a negative value. According to the thermal compression curves of the $\mathrm{Mg}-2.5 \mathrm{Nd}-0.5 \mathrm{Zn}-0.5 \mathrm{Zr}$ alloy in Figure 2, the flow stress at different deformation temperatures $(\mathrm{T})$, strain rates $(\dot{\varepsilon})$ and strain variables $(\varepsilon)$ was obtained, and the relationship of the $\ln \sigma-\ln \dot{\varepsilon}$ at given strain conditions was plotted. Figure 9 shows the $\ln \sigma-\ln \dot{\varepsilon}$ at the strain variables of $0.1,0.3$ and 0.5 . The $\ln \sigma$ and $\ln \dot{\varepsilon}$ had good linear correlations. This indicated that the stress-strain of the Mg-2.5Nd-0.5Zn-0.5Zr alloy in the range of $573-773 \mathrm{~K} / 0.001-10 \mathrm{~s}^{-1}$ followed the power equation of Equation (15). This 
showed that the DMM and Prasad criterion could be used to draw the processing maps of the $\mathrm{Mg}-2.5 \mathrm{Nd}-0.5 \mathrm{Zn}-0.5 \mathrm{Zr}$ alloy under different strain conditions.

(a)

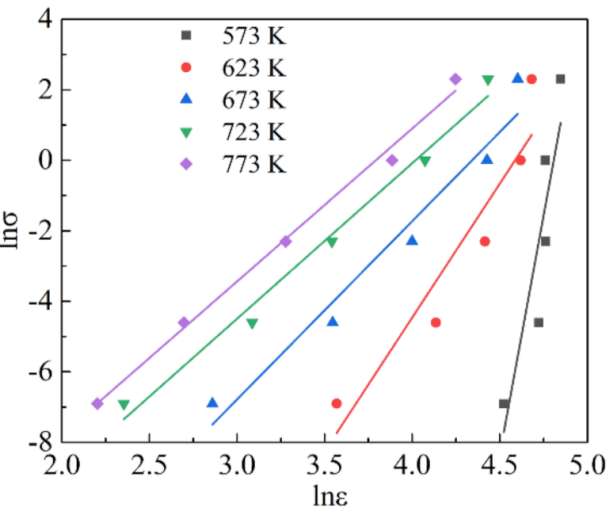

(b)

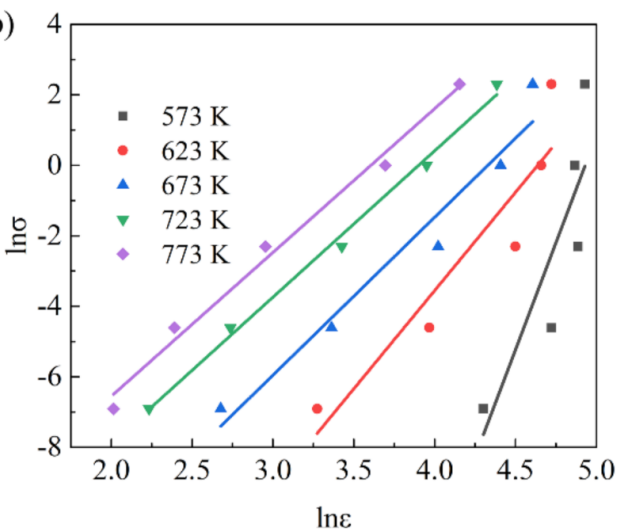

(c)

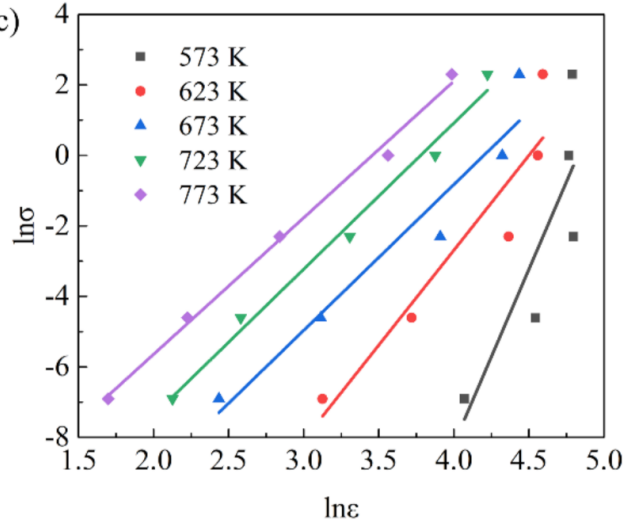

Figure 9. The relationship of $\ln \sigma-\ln \dot{\varepsilon},(\mathbf{a}) \varepsilon=0.1$, (b) $\varepsilon=0.3$, (c) $\varepsilon=0.5$.

Figure 10 shows the processing maps and instability diagram which were superposed by power dissipation diagram and the stress-strain curve of the $\mathrm{Mg}-2.5 \mathrm{Nd}-0.5 \mathrm{Zn}-0.5 \mathrm{Zr}$ alloy at strain variables $0.1,0.3$ and 0.5 , respectively. The value of the isoline in the figure represents the percentage of the power dissipation factor $(\eta)$, which represents the energy consumed by the change of the tissue during thermal deformation. Generally, the value of $\eta$ corresponding to DRV ranged from 20 to $30 \%$, whereas that of DRX pairs was above $30 \%$. In Figure 10, the gray shaded area represents the region where $\xi(\dot{\varepsilon})$ was less than 0 , i.e., the instability zone of plastic flow. When $\varepsilon$ was $0.1, \eta$ increased with increased temperature and decreased with strain rate in the range of $573 \sim 723 \mathrm{~K}$. At $773 \mathrm{~K}$, the value of $\eta$ showed a decreased trend. When $\varepsilon$ was 0.3 and 0.5 , the variation law was essentially the same as when $\varepsilon$ was 0.1 . When $\varepsilon$ was 0.1 , the $\eta$ of the instability zone was less than $30 \%$. The instability zones were two discontinuous zones at $573-592 \mathrm{~K}$ and $0.001-0.555 \mathrm{~s}^{-1}$, and $759-773 \mathrm{~K}$ and $2.513-10 \mathrm{~s}^{-1}$. The stable region was at $592-773 \mathrm{~K}$ and $0.001-10 \mathrm{~s}^{-1}$. When the $\varepsilon$ increased to 0.3 , the $\eta$ of the instability region reached $35 \%$, and the instability region was $573-773 \mathrm{~K}$ and $0.003-1.176 \mathrm{~s}^{-1}$. The stable regions were $573-610 \mathrm{~K}$ and $0.001-0.003 \mathrm{~s}^{-1}$, $610-705 \mathrm{~K}$ and $0.003-0.441 \mathrm{~s}^{-1}, 705-773 \mathrm{~K}$ and $0.411-9.081 \mathrm{~s}^{-1}$, respectively. When the strain increased to 0.5 , the $\eta$ of the instability region reached $42 \%$, and the instability zone was $573-773 \mathrm{~K}$ and $0.002-4.758 \mathrm{~s}^{-1}$. The stable regions were $573-597 \mathrm{~K}$ and $0.001-0.004 \mathrm{~s}^{-1}$, 597-664 $\mathrm{K}$ and $0.004-0.181 \mathrm{~s}^{-1}, 664-773 \mathrm{~K}$ and $0.181-1.416 \mathrm{~s}^{-1}$, respectively. In summary, the best processing area was $592-773 \mathrm{~K}$ and $0.001-0.217 \mathrm{~s}^{-1}$. 

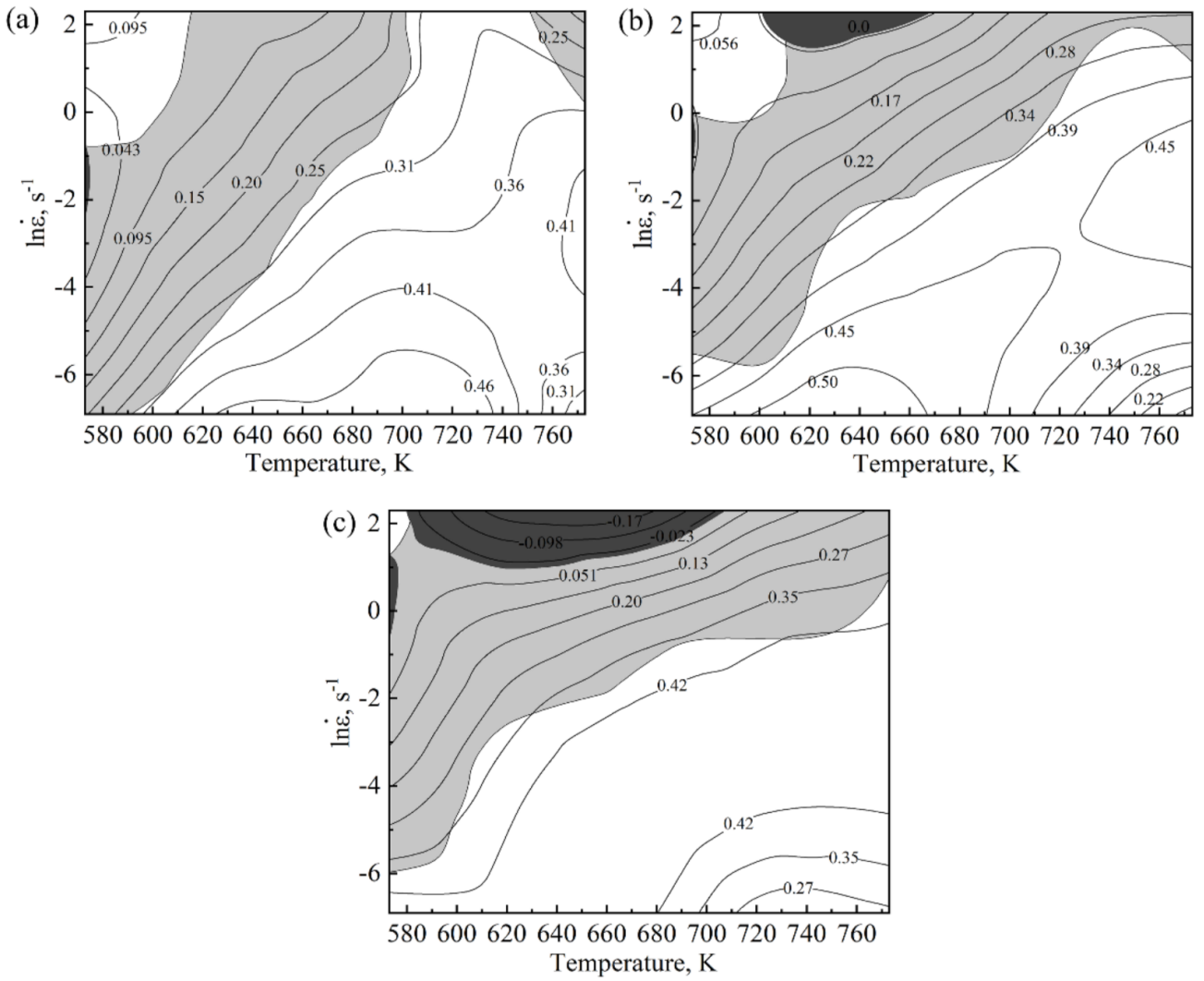

Figure 10. The processing map of the Mg-2.5Nd-0.5Zn-0.5Zr alloy, (a) $\varepsilon=0.1$, (b) $\varepsilon=0.3$, (c) $\varepsilon=0.5$.

\subsection{Microstructure Evolution of the Compression Alloy Was Analyzed by EBSD}

Figure 11 exhibits the EBSD figures and 3D grain size distribution diagrams of the $\mathrm{Mg}$ $2.5 \mathrm{Nd}-0.5 \mathrm{Zn}-0.5 \mathrm{Zr}$ alloy in various hot deformation conditions. In this study, the method for distinguishing recrystallized and deformed grains was that described in Ref. [3]. With the increase in deformation temperature, the grain size of the alloy gradually grew. The average grain sizes were $3.9 \pm 1.8 \mu \mathrm{m}(573 \mathrm{~K}), 4.6 \pm 2.7 \mu \mathrm{m}(623 \mathrm{~K}), 5.9 \pm 2.3 \mu \mathrm{m}(673 \mathrm{~K})$, $12.1 \pm 6.7 \mu \mathrm{m}(723 \mathrm{~K})$ and $31.8 \pm 15.8 \mu \mathrm{m}(773 \mathrm{~K})$, respectively (Figure 11f). The grain size of the alloy grew slowly in the 573-673 K deformation temperature range. The grain size of the alloy grew rapidly in the 723-773 K deformation temperature range. The Zener-Hollomon $\left(\mathrm{Z}=\dot{\varepsilon} \exp \left(-\frac{\mathrm{Q}}{\mathrm{RT}}\right)\right)$ parameters determine whether dynamic recrystallized grains were refined during plastic deformation [22]. With the increase in deformation temperature, the $Z$ value was larger, which weakened the grain refining effect of DRX and resulted in coarse recrystallized grains [15]. Meanwhile, the grain boundary migration speed was accelerated, and grains noticeably grew [32]. The recrystallization proportions of the alloys were $75.5 \%$ (573 K), 59.8\% (623 K), 67.5\% (673 K), 65.5\% (723 K) and 84.5\% (773 K), respectively. Interestingly, the hot compression experiment was not a transient process, and new dynamically recrystallized grains were involved in deformation during nucleation and growth. Hence, the degree of DRX could only be explained qualitatively according to the information in the GOS figure, while the actual DRX was different from that described in the GOS figure [30-41]. 

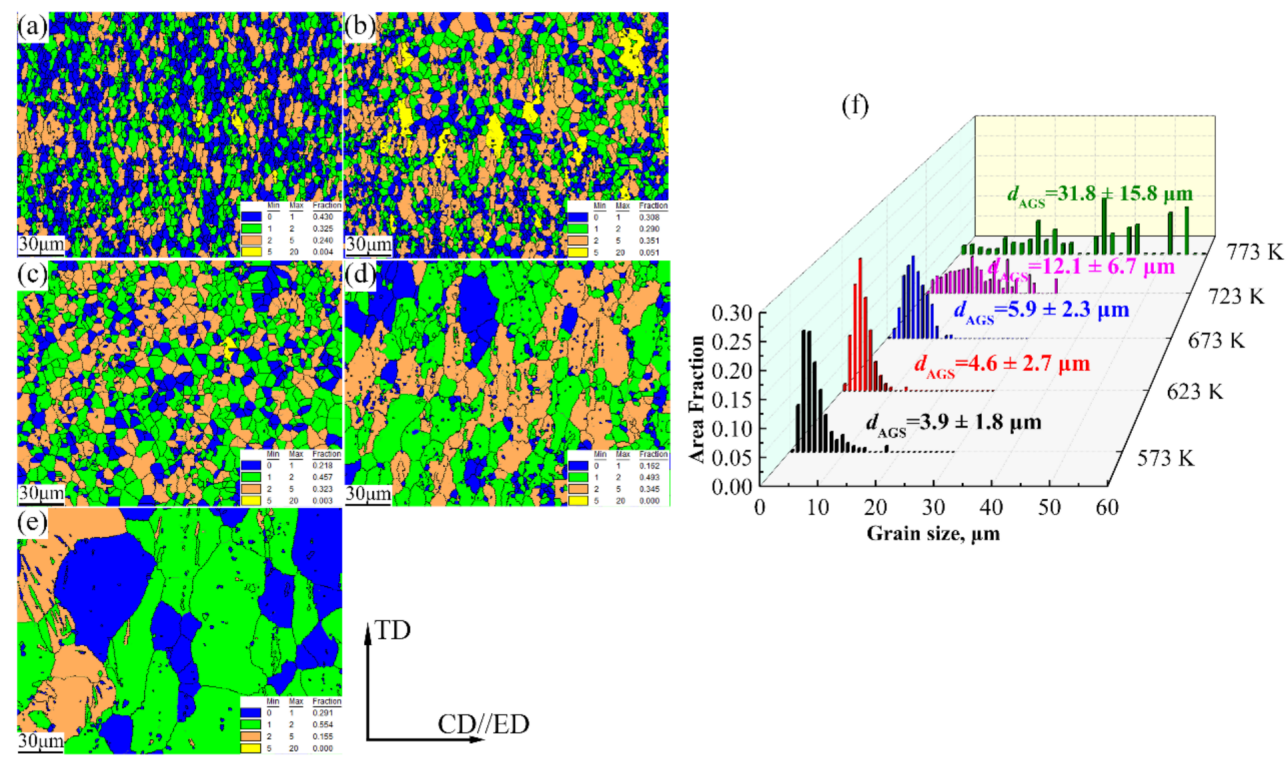

Figure 11. GOS maps of the Mg-2.5Nd-0.5Zn-0.5Zr alloy deformed at different temperatures and a strain rate of $0.001 \mathrm{~s}^{-1}$, (a) $573 \mathrm{~K}$, (b) $623 \mathrm{~K}$, (c) $673 \mathrm{~K}$, (d) $723 \mathrm{~K}$, (e) $773 \mathrm{~K}$ and (f) grain size distribution. (ED: extrusion direction, $\mathrm{CD}$ : compression direction, TD: transverse direction).

Figure 12 presents the GB figures of the $\mathrm{Mg}-2.5 \mathrm{Nd}-0.5 \mathrm{Zn}-0.5 \mathrm{Zr}$ alloy at various hot deformations. During hot deformation, dislocations accumulated and rearranged at grain boundaries and severely deformed regions, forming low-angle grain boundaries (LAGBs) [2]. With the increase in deformation temperature, LAGBs were transformed into subgrains by absorbing surrounding dislocation, and the sub-grains grew to form highangle grain boundaries (HAGBs). LAGBs continuously absorbed dislocations into HAGBs, resulting in a significant increase in HAGBs. Meanwhile, the increase in HAGBs meant that the stored dislocation was consumed, which was consistent with the characteristics of CDRX [30]. As shown in Figure 12, with the increase in deformation temperature, the proportion of HAGBs of the alloy increased first, then decreased and finally increased. When the deformation temperature was $773 \mathrm{~K}$, the recrystallization ratio of the alloy was $84.5 \%$, which indicates that the ability of LAGBs to absorb dislocation and transform into HAGBs was improved at high temperatures, providing a sufficient driving force for DRX [42]. This was consistent with the recrystallization trend of the alloy shown in Figure 11.

Figure 13 depicts the KAM of the Mg-2.5Nd-0.5Zn-0.5Zr alloy at various hot deformations. The KAM diagram was calculated based on the local offset level between a single point (core) and all surrounding points and was usually used to represent the internal plastic strain of the alloy. The higher the KAM value was, the greater the plastic deformation degree was, and the greater the geometry had to be dislocated. The geometry dislocation calculation method was that described in Refs. $[6,15]$. The gradual change from blue to red in the KAM maps shows that the local directional deviation was gradually increasing. In Figure 13 , it is shown that the KAM values of the alloy were $0.607177^{\circ}(573 \mathrm{~K}), 0.787447^{\circ}$ $(623 \mathrm{~K}), 0.506911^{\circ}(673 \mathrm{~K}), 0.806071^{\circ}(723 \mathrm{~K})$ and $0.635908^{\circ}(773 \mathrm{~K})$, respectively. The calculated geometry must have had dislocations of $1.324 \times 10^{-4} \mathrm{~nm}^{-2}(573 \mathrm{~K}), 1.717 \times 10^{-4} \mathrm{~nm}^{-2}$ $(623 \mathrm{~K}), 1.105 \times 10^{-4} \mathrm{~nm}^{-2}(673 \mathrm{~K}), 1.758 \times 10^{-4} \mathrm{~nm}^{-2}(723 \mathrm{~K})$ and $1.387 \times 10^{-4} \mathrm{~nm}^{-2}$ (773 K), respectively. However, no matter what the deformation temperature was, the local misorientation was not uniform during hot compression, and the misorientation at the grain boundary was generally higher than that in the grain [30]. These results indicate that the dislocation accumulation at the grain boundary was severe and the deformation storage was large, which provided the energy for DRX nucleation. In addition, the atoms on the grain boundary were rearranged irregularly and the lattice distortion was relatively large, which made the absorption of various impurity elements easy. Therefore, in the process of plastic deformation, grain boundaries hinder dislocation movement, and dislocation 
stacking groups tend to appear in front of grain boundaries [30]. As shown in Figure 13, with the increase in deformation temperature, local deflection first increases, then decreases, then increases and then decreases. This indicates that DRX occurs at the cost of dislocation consumption during hot compression. When this is combined with Figure 11, it can be seen that when the deformation temperature of the alloy was $773 \mathrm{~K}$, the recrystallization ratio was relatively high and dislocation consumption was relatively large. Therefore, the $\rho_{\mathrm{GND}}$ was relatively small.

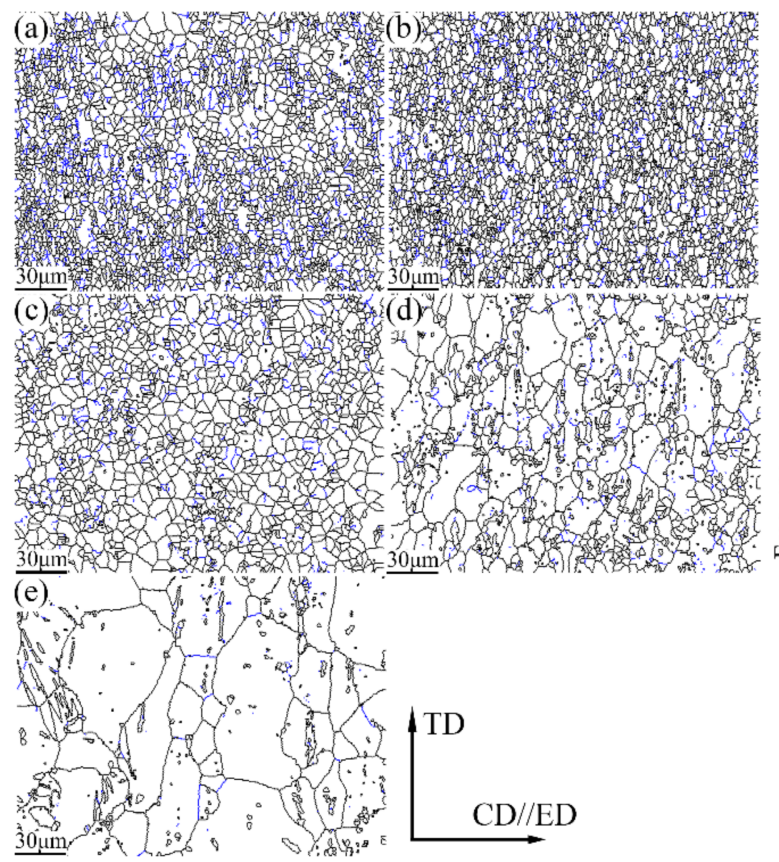

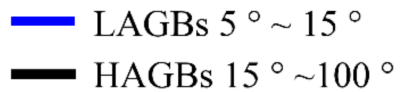

(f)

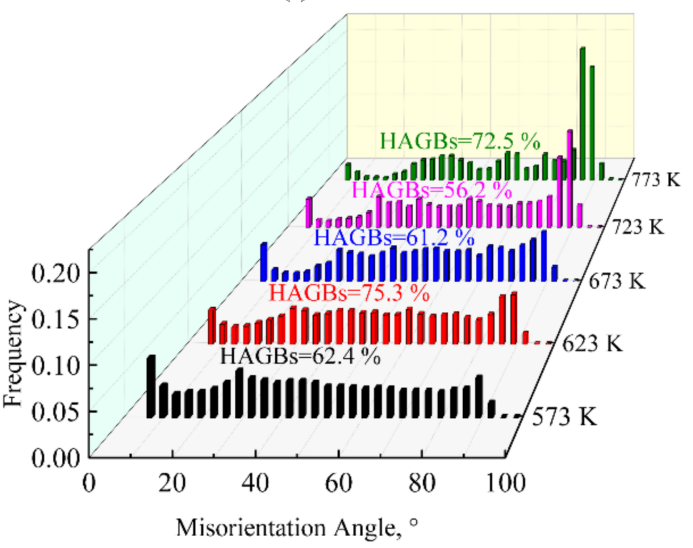

Figure 12. Grain boundary maps of the Mg-2.5Nd-0.5Zn-0.5Zr alloy deformed at different temperatures and a strain rate of $0.001 \mathrm{~s}^{-1}$. Black lines refer to HAGBs $\left(>15^{\circ}\right)$, blue lines to LAGBs $\left(5 \sim 15^{\circ}\right)$, (a) $573 \mathrm{~K}$, (b) $623 \mathrm{~K}$, (c) $673 \mathrm{~K}$, (d) $723 \mathrm{~K}$, (e) $773 \mathrm{~K}$ and (f) Misorientation angle distribution.

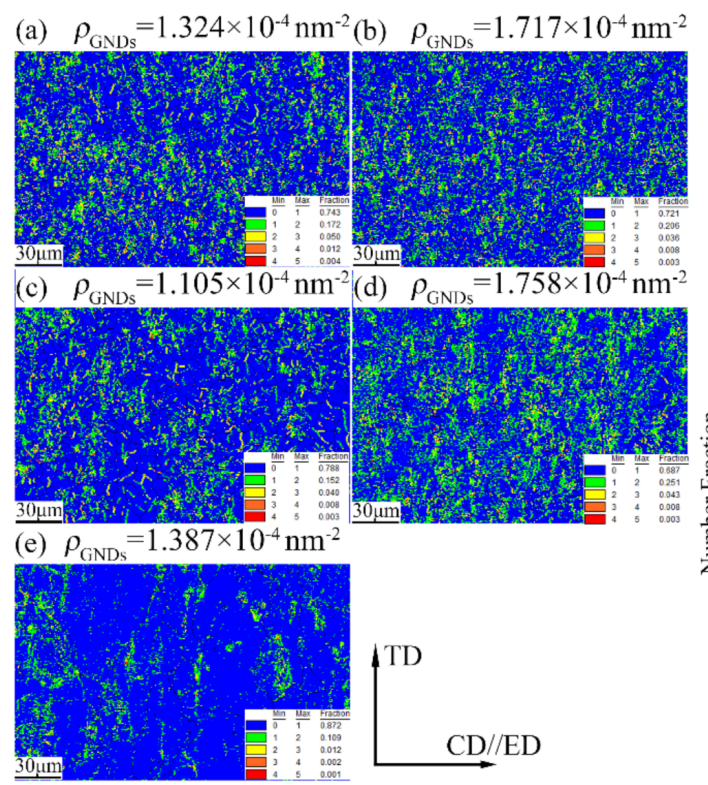

(f)

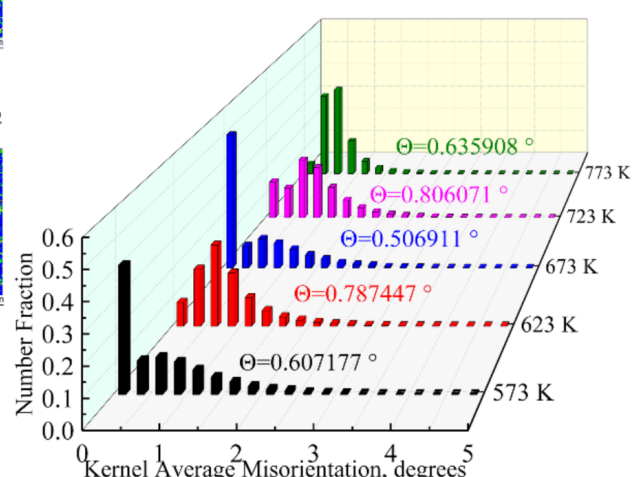

Figure 13. The kernel average misorientation of the $\mathrm{Mg}-2.5 \mathrm{Nd}-0.5 \mathrm{Zn}-0.5 \mathrm{Zr}$ alloy deformed at different temperatures and a strain rate of $0.001 \mathrm{~s}^{-1}$. (a) $573 \mathrm{~K}$, (b) $623 \mathrm{~K}$, (c) $673 \mathrm{~K}$, (d) $723 \mathrm{~K}$, (e) $773 \mathrm{~K}$ and (f) kernel average misorientation distribution. 


\section{Conclusions}

In this paper, the high-temperature deformation behavior of the Mg-2.5Nd-0.5Zn$0.5 \mathrm{Zr}$ alloy in the range of $573-773 \mathrm{~K}$ and $0.001-10 \mathrm{~s}^{-1}$ was studied using an isothermal compression experiment system. The main results were as follows:

(1) The flow stress of the $\mathrm{Mg}-2.5 \mathrm{Nd}-0.5 \mathrm{Zn}-0.5 \mathrm{Zr}$ alloy in the range of $573-773 \mathrm{~K} /$ 0.001-10 $\mathrm{s}^{-1}$ was very sensitive to the deformation temperature, strain rate and strain variables. The whole hot-working process was divided into three stages: work hardening, dynamic softening and dynamic balancing.

(2) A hyperbolic Arrhenius-type strain compensation constitutive model with high accuracy for the Mg-2.5Nd-0.5Zn-0.5Zr alloy was established. This constitutive model had high acceptable predictability. The dominant deformation mechanism of the $\mathrm{Mg}-2.5 \mathrm{Nd}-$ $0.5 \mathrm{Zn}-0.5 \mathrm{Zr}$ alloy was dislocation climbing.

(3) The thermal processing maps of the $\mathrm{Mg}-2.5 \mathrm{Nd}-0.5 \mathrm{Zn}-0.5 \mathrm{Zr}$ alloy under different strains were established, and the optimal processing range was determined to be $592-773 \mathrm{~K}$ and $0.001-0.217 \mathrm{~s}^{-1}$.

(4) With the increase in deformation temperature, the grain size of the $\mathrm{Mg}-2.5 \mathrm{Nd}$ $0.5 \mathrm{Zn}-0.5 \mathrm{Zr}$ alloy grew slowly at the $573-673 \mathrm{~K}$ temperature range and grew rapidly at the 673-773 K temperature range.

Highlights:

1. Hot deformation was performed in compressive modes.

2. A manufacturability map of the $\mathrm{Mg}-2.5 \mathrm{Nd}-0.5 \mathrm{Zn}-0.5 \mathrm{Zr}$ alloy was established for the first time.

3. A strain-compensated constitutive model for determining flow stress in this alloy was established with highly acceptable predictability.

4. The dominant deformation mechanism of the alloy was dislocation climbing.

Author Contributions: Conceptualization, S.W. and J.M.; methodology, J.Y.; software, W.C.; validation, S.W., J.Y. and W.Z.; formal analysis, W.C.; investigation, G.C. (Guannan Chu); resources, G.C. (Guorong Cui) and G.C. (Guannan Chu); data curation, J.Y.; writing-original draft preparation, J.M.; writing—review and editing, S.W.; visualization, W.Z.; supervision, G.C. (Guorong Cui); project administration, S.W.; funding acquisition, W.Z. and G.C. (Guannan Chu). All authors have read and agreed to the published version of the manuscript.

Funding: Key Research and Development Plan in Shandong Province (Grant No. 2019JZZY010364), Space Science and Technology Fund of China (Grant No. JZJJX20190024), Key Program of National Natural Science Foundation of China (Grant No. U1937205) and Key Research and Development Program of Shandong (Grant No. 2020CXGC010303).

Institutional Review Board Statement: Not applicable.

Informed Consent Statement: Not applicable.

Data Availability Statement: The data presented in this study are available on request from the corresponding author. The data are not publicly available due to their association with an ongoing study.

Acknowledgments: This work was supported by the Key Research and Development Plan in Shandong Province (Grant No. 2019JZZY010364), the Space Science and Technology Fund of China (Grant No. JZJJX20190024), the Key Program of National Natural Science Foundation of China (Grant No. U1937205) and the Key Research and Development Program of Shandong (Grant No. 2020CXGC010303).

Conflicts of Interest: The authors declare no conflict of interest. 


\section{References}

1. Xu, C.; Zheng, M.Y.; Wu, K.; Wang, E.D.; Fan, G.H.; Xu, S.W.; Kamado, S.; Liu, X.D.; Wang, G.J.; Lv, X.Y. Influence of rolling temperature on the microstructure and mechanical properties of Mg-Gd-Y-Zn-Zr alloy sheets. Mater. Sci. Eng. A 2013, 559, 615-622. [CrossRef]

2. Zhang, Q.; Li, Q.A.; Chen, X.Y.; Zhao, J.X.; Bao, J.; Chen, Z.Y. Dynamic precipitation and recrystallization mechanism during hot compression of Mg-Gd-Y-Zr alloy. J. Mater. Res. Technol. 2021, 15, 37-51. [CrossRef]

3. Wang, S.H.; Zhang, W.C.; Yang, J.L.; Pan, J.Q.; Wang, H.X.; Chen, W.Z.; Cui, G.R. Evolution of microstructures, texture, damping and mechanical properties of hot extruded Mg-Nd-Zn-Zr alloy. J. Mater. Eng. Perform. 2021, 30, 8872-8882. [CrossRef]

4. Sun, W.T.; Qiao, X.G.; Zheng, M.Y.; Xu, C.; Kamado, S.; Zhao, X.J.; Chen, H.W.; Gao, N.; Starink, M.J. Altered ageing behaviour of a nanostructured Mg-8.2Gd-3.8Y-1.0Zn-0.4Zr alloy processed by high pressure torsion. Acta Mater. 2018, 151, 260-270. [CrossRef]

5. MacLeod, S.G.; Errandonea, D.; Cox, G.A.; Cynn, H.; Daisenberger, D.; Finnegan, S.E.; McMahon, M.I.; Munro, K.A.; Popescu, C.; Storm, C.V. The phase diagram of Ti-6Al-4V at high-pressures and high-temperatures. J. Phys. Condens. Matter 2021, $33,154001$. [CrossRef]

6. Camin, B.; Gille, M. The effect of specimen size and test procedure on the creep behavior of ME21 magnesium alloy. Crystals 2021, 11, 918. [CrossRef]

7. Smith, D.; Joris, O.P.J.; Sankaran, A.; Weekes, H.E.; Bull, D.J.; Prior, T.J.; Dye, D.; Errandonea, D.; Proctor, J.E. On the high-pressure phase stability and elastic properties of $\beta$-titanium alloys. J. Phys. Condens. Matter 2017, 29, 155401. [CrossRef]

8. Su, N.; Wu, Y.J.; Deng, Q.C.; Chang, Z.Y.; Wu, Q.Y.; Xue, Y.T.; Yang, K.; Chen, Q.; Peng, L.M. Synergic effects of Gd and Y contents on the age-hardening response and elevated-temperature mechanical properties of extruded Mg-Gd(-Y)-Zn-Mn alloys. Mater. Sci. Eng. A 2021, 810, 141019. [CrossRef]

9. Hou, X.L.; Cao, Z.Y.; Wang, L.D.; Xu, S.W.; Kamado, S.; Wang, L.M. Microstructure and mechanical properties of extruded Mg-8Gd-2Y-1Nd-0.3Zn-0.6Zr alloy. Mater. Sci. Eng. A 2011, 528, 7805-7810. [CrossRef]

10. Lei, B.; Jiang, B.; Yang, H.B.; Dong, Z.H.; Wang, Q.H.; Yuan, M.; Huang, G.S.; Song, J.F.; Zhang, D.F.; Pan, F.S. Effect of Nd addition on the microstructure and mechanical properties of extruded Mg-Gd-Zr alloy. Mater. Sci. Eng. A 2021, 816, 141320. [CrossRef]

11. Fu, P.H.; Peng, L.M.; Jiang, H.Y.; Chang, J.W.; Zhai, C.Q. Effects of heat treatments on the microstructures and mechanical properties of Mg-3Nd-0.2Zn-0.4Zr (wt.\%) alloy. Mater. Sci. Eng. A 2008, 486, 183-192. [CrossRef]

12. He, S.M.; Zeng, X.Q.; Peng, L.M.; Gao, X.; Nie, J.F.; Ding, W.J. Microstructure and strengthening mechanism of high strength Mg-10Gd-2Y-0.5Zr alloy. J. Alloy. Compd. 2007, 427, 316-323. [CrossRef]

13. Li, B.S.; Guan, K.; Yang, Q.; Niu, X.D.; Zhang, D.D.; Lv, S.H.; Meng, F.Z.; Huang, Y.D.; Hort, N.; Meng, J. Microstructures and mechanical properties of a hot-extruded Mg-8Gd-3Yb-1.2Zn-0.5Zr (wt\%) alloy. J. Alloy. Compd. 2019, 776, 666-678. [CrossRef]

14. Zhou, Y.Y.; Fu, P.H.; Peng, L.M.; Wang, D.; Wang, Y.X.; Hu, B.; Liu, M.; Sachdev, A.K.; Ding, W.J. Precipitation modification in cast Mg-1Nd-1Ce-Zr alloy by Zn addition. J. Magnes. Alloy. 2019, 7, 113-123. [CrossRef]

15. Wang, S.H.; Zhang, W.C.; Wang, H.X.; Yang, J.L.; Chen, W.Z.; Cui, G.R.; Wang, G.F. Microstructures evolution, texture characteristics and mechanical properties of $\mathrm{Mg}-2.5 \mathrm{Nd}-0.5 \mathrm{Zn}-0.5 \mathrm{Zr}$ alloy during the high strain rate hot-rolling. Mater. Sci. Eng. A 2021, 803, 140488. [CrossRef]

16. Chen, W.Z.; Ma, J.F.; Cui, C.; Zhang, W.C.; Wang, W.K.; Liu, X.T.; Yang, J.L.; Cui, G.R. Texture role in the mechanical property improvement contributed by grain refinement for $\mathrm{Mg}-2.6 \mathrm{Nd}-0.55 \mathrm{Zn}-0.5 \mathrm{Zr}$ alloy subjected to extrusion process. Mater. Sci. Eng. A 2022, 831, 142185. [CrossRef]

17. Zhao, S.C.; Guo, E.J.; Cao, G.J.; Wang, L.P.; Lun, Y.C.; Feng, Y.C. Microstructure and mechanical properties of Mg-Nd-Zn-Zr alloy processed by integrated extrusion and equal channel angular pressing. J. Alloy. Compd. 2017, 705, 118-125. [CrossRef]

18. Gui, Z.Z.; Kang, Z.X.; Li, Y.Y. Evolution of the microstructure and fracture characteristics of a Mg-Nd-Zn-Zr-Mn alloy through heat treatment and extrusion. J. Alloy. Compd. 2018, 765, 470-479. [CrossRef]

19. Zhu, S.Q.; Yan, H.G.; Chen, J.H.; Wu, Y.Z.; Su, B.; Du, Y.G.; Liao, X.Z. Feasibility of high strain-rate rolling of a magnesium alloy across a wide temperature range. Scr. Mater. 2012, 67, 404-407. [CrossRef]

20. Fu, P.H.; Peng, L.M.; Jiang, H.Y.; Ma, L.; Zhai, C.Q. Chemical composition optimization of gravity cast Mg-yNd-xZn-Zr alloy. Mater. Sci. Eng. A 2008, 496, 177-188. [CrossRef]

21. Hoseini-Athar, M.M.; Mahmudi, R.; Babu, R.P.; Hedstrom, P. Microstructure, texture, and strain-hardening behavior of extruded Mg-Gd-Zn alloys. Mater. Sci. Eng. A 2020, 772, 138833. [CrossRef]

22. Hu, L.; Lang, M.W.; Shi, L.X.; Li, M.G.; Zhou, T.; Bao, C.L.; Yang, M.B. Study on hot deformation behavior of homogenized Mg-8.5Gd-4.5Y-0.8Zn-0.4Zr alloy using a combination of strain-compensated Arrhenius constitutive model and finite element simulation method. J. Magnes. Alloy. 2021, in press. [CrossRef]

23. Xia, X.S.; Chen, Q.; Zhang, K.; Zhao, Z.D.; Ma, M.L.; Li, X.G.; Li, Y.J. Hot deformation behavior and processing map of coarse-grained Mg-Gd-Y-Nd-Zr alloy. Mater. Sci. Eng. A 2013, 587, 283-290. [CrossRef]

24. Yu, C.Q.; Feng, Y.C.; Zhang, J.P.; Wang, L.; Zhao, S.C.; Wang, L.P. Effect of initial microstructure conditions on the microstructure and mechanical properties of hot extruded Mg-6Nd-2Al alloy. J. Mater. Eng. Perform. 2022, 31, 742-752. [CrossRef]

25. Bembalge, O.B.; Panigrahi, S.K. Hot deformation behavior and processing map development of cryorolled AA6063 alloy under compression and tension. Int. J. Mech. Sci. 2021, 191, 106100. [CrossRef]

26. Lei, C.; Wang, Q.D.; Tang, H.P.; Liu, T.W.; Li, Z.Y.; Jiang, H.Y.; Wang, K.; Ebrahimi, M.; Ding, W.J. Hot deformation constitutive model and processing maps of homogenized Al-5Mg-3Zn-1Cu alloy. J. Mater. Res. Technol. 2021, 14, 324-339. [CrossRef] 
27. Yang, J.L.; Wang, G.F.; Jiao, X.Y.; Li, Y.; Liu, Q. High-temperature deformation behavior of the extruded Ti-22Al-25Nb alloy fabricated by powder metallurgy. Mater. Charact. 2018, 137, 170-179. [CrossRef]

28. Yang, J.L.; Wang, G.F.; Jiao, X.Y.; Li, X.; Yang, C. Hot deformation behavior and microstructural evolution of Ti-22Al-25Nb-1.0B alloy prepared by elemental powder metallurgy. J. Alloy. Compd. 2017, 695, 1038-1044. [CrossRef]

29. Chen, Q.; Hu, L.; Li, M.G.; Chen, Y.; Shi, L.X.; Zhou, T.; Yang, M.B. Optimizing process parameters of as-homogenized Mg-Gd-Y$\mathrm{Zn}-\mathrm{Zr}$ alloy in isothermal uniaxial compression on the basis of processing maps via prasad criterion and murty criterion. J. Mater. Eng. Perform. 2021, 5, 1-10. [CrossRef]

30. Zhang, Q.; Li, Q.A.; Chen, X.Y.; Bao, J.; Chen, Z.Y. Effect of Sn addition on the deformation behavior and microstructural evolution of Mg-Gd-Y-Zr alloy during hot compression. Mater. Sci. Eng. A 2021, 826, 142026. [CrossRef]

31. Zheng, X.W.; Luo, P.; Han, Z.L. Hot deformation behavior and processing map of high-strength Mg-2.5Nd-0.2Zn-1.0Zr alloy. J. Mater. Eng. Perform. 2022, 31, 1222-1230. [CrossRef]

32. Wang, S.H.; Ma, J.F.; Yang, J.L.; Zhang, W.C.; Sun, Y.P.; Pan, J.Q.; Wang, H.X.; Chen, W.Z. Improving the ductility of Mg-2.5Nd0.5Zn-0.5Zr alloy by multi-pass hot rolling. J. Mater. Res. Technol. 2021, 14, 2124-2130. [CrossRef]

33. Bohlen, J.; Nuürnberg, M.R.; Senn, J.W.; Letzig, D.; Agnew, S.R. The texture and anisotropy of magnesium-zinc-rare earth alloy sheets. Acta Mater. 2007, 55, 2101-2112. [CrossRef]

34. Robson, J.D.; Henry, D.T.; Davis, B. Particle effects on recrystallization in magnesium-manganese alloys: Particle-stimulated nucleation. Acta Mater. 2009, 57, 2739-2747. [CrossRef]

35. Basu, I.; Al-Samman, T. Triggering rare earth texture modification in magnesium alloys by addition of zinc and zirconium. Acta Mater. 2014, 67, 116-133. [CrossRef]

36. Deng, K.K.; Li, J.C.; Xu, F.J.; Nie, K.B.; Liang, W. Hot deformation behavior and processing maps of fine-grained SiCp/AZ91 composite. Mater. Des. 2015, 67, 72-81. [CrossRef]

37. Vagarali, S.S.; Langdon, T.G. Deformation mechanisms in h.c.p. metals at elevated temperatures-II. Creep behavior of a Mg- $0.8 \%$ Al solid solution alloy. Acta Mater. 1982, 30, 1157-1170. [CrossRef]

38. Wang, Y.X.; Zhao, G.Q.; Xu, X.X.; Chen, X.X.; Zhang, C.S. Constitutive modeling, processing map establishment and microstructure analysis of spray deposited Al-Cu-Li alloy 2195. J. Alloy. Compd. 2019, 779, 735-751. [CrossRef]

39. Yang, Q.B.; Wang, X.Z.; Li, X.; Deng, Z.H.; Jia, Z.H.; Zhang, Z.Q.; Huang, G.J.; Liu, Q. Hot deformation behavior and microstructure of AA2195 alloy under plane strain compression. Mater. Charact. 2017, 131, 500-507. [CrossRef]

40. Sahoo, B.N.; Panigrahi, S.K. Deformation behavior and processing map development of AZ91 Mg alloy with and without addition of hybrid in-situ TiC+TiB2 reinforcement. J. Alloy. Compd. 2019, 776, 865-882. [CrossRef]

41. Liu, Z.G.; Li, P.J.; Xiong, L.T.; Liu, T.Y.; He, L.J. High-temperature tensile deformation behavior and microstructure evolution of Ti55 titanium alloy. Mater. Sci. Eng. A 2017, 680, 259-269. [CrossRef]

42. Fan, D.G.; Deng, K.K.; Wang, C.J.; Nie, K.B.; Shi, Q.X.; Liang, W. Hot deformation behavior and dynamic recrystallization mechanism of an Mg-5wt.\%Zn alloy with trace SiCp addition. J. Mater. Res. Technol. 2021, 10, 422-437. [CrossRef] 